\title{
ALTERNATIVAS DE PLANEJAMENTO PARA A EXPLORAÇÃO FLORESTAL
}

\author{
Ana Paula Donicht Fernandes ${ }^{1}$, Pompeu Paes Guimarães ${ }^{2}$, Evaldo Muñoz Braz ${ }^{3}$, \\ Vitor Afonso Hoeflich ${ }^{4}$, Julio Eduardo Arce ${ }^{5}$ \\ ${ }^{1}$ Eng ${ }^{\mathrm{a}}$ Florestal, Mestranda em Engenharia Florestal, UFPR, Curitiba, PR, Brasil - anapauladfernandes@ yahoo.com.br \\ ${ }^{2}$ Eng. Florestal, M.Sc., Doutorando em Engenharia Florestal, UFPR, Prof. Auxiliar da UFERSA, Mossoró, RN, Brasil - \\ pompeu.guimaraes@ufersa.edu.br \\ ${ }^{3}$ Eng. Florestal, Dr., Embrapa Florestas, Colombo, PR, Brasil - evaldo.braz@embrapa.br \\ ${ }^{4}$ Eng. Agrônomo, Dr., Depto. de Economia Rural e Extensão, UFPR, Curitiba, PR, Brasil - vitor.ufpr@ gmail.com \\ ${ }^{5}$ Eng. Florestal, Dr., Depto. de Ciências Florestais, UFPR, Curitiba, PR, Brasil - jarce@ufpr.br \\ Recebido para publicação: 26/02/2013 - Aceito para publicação: 10/07/2013
}

\begin{abstract}
Resumo
No manejo sustentado em florestas tropicais, há necessidade da garantia de um fluxo constante de recursos para a sua viabilidade. No entanto, isso nem sempre é possível, pelo fato de a exploração ser realizada sem planejamento. Este trabalho tem como finalidade apresentar um método que auxilie no planejamento e na distribuição de recursos disponíveis, através da formulação de cenários para otimização do número de equipes para cada atividade da exploração dependente do tempo limite para conclusão dos trabalhos. Com base no tempo que uma equipe leva para executar determinada atividade e no seu sequenciamento, foram utilizadas técnicas da pesquisa operacional, para determinação do caminho crítico da cadeia de exploração de madeira nativa. Esses métodos, ao mesmo tempo em que organizam o sequenciamento das atividades e determinam quais delas devem receber maior atenção no planejamento, otimizam o número de equipes, para que toda a cadeia seja executada dentro de um tempo limite, o que se faz necessário na região, para que o ciclo de corte se limite à época de seca. $\mathrm{O}$ método proposto mostra-se como uma alternativa para o planejamento florestal das atividades de baixo impacto ao garantir o número ótimo de equipes e a realização de todo empreendimento no tempo estipulado.
\end{abstract}

Palavras-chave: Manejo florestal de baixo impacto; programação matemática; PERT/CPM.

\begin{abstract}
Planning alternatives for forestry exploitation. It is necessary to ensure a steady flow of funds for feasibility of sustainable management in tropical forests. However, this is not always possible, due to often not planned forest exploitation. This research aims to present a method that assists planning and distribution of resources, by scenarios formulating, in order to optimize the number of teams for each exploitation activity under time limit to its conclusion. Based on time that a team uses to perform a certain activity and its sequence, it used operations research techniques, such as linear programming and PERT/CPM, in order to determine the critical path of the exploitation chain of native wood. These methods, arranging the sequence of activities and determining which ones should receive more attention in planning, optimize the number of teams in order to perform the chain within a time limit, which is necessary for the region, once the cutting cycle should be limited to the dry season. As result, the proposed method proves to be a good alternative for forest planning of low impact activities ensuring the optimal number of teams and performing the entire project in stipulated time. Keywords: Forest low impact exploitation; math programming; PERT/CPM.
\end{abstract}

\section{INTRODUÇÃO}

O manejo florestal constitui, atualmente, uma técnica de conservação dos ecossistemas que propicia o uso da madeira de forma planejada, a melhoria das condições de vida das populações e a manutenção da floresta. Dessa forma, o manejo tende a aliar as demandas do setor de forma tecnificada e sustentada (PINHO et al., 2009). 
A garantia do aproveitamento dos recursos madeireiros e não madeireiros de forma contínua, associada à conservação da biodiversidade de florestas nativas, como a Amazônia, pode ser alcançada mediante o Manejo Florestal Sustentável (MFS). A finalidade do manejo florestal é conseguir que as florestas forneçam continuamente benefícios econômicos, ecológicos e sociais, mediante o planejamento da exploração florestal, visando o mínimo impacto (GAMA et al., 2005).

A exploração florestal é um termo utilizado para definir um conjunto de operações que inicia com a abertura de acesso à floresta e termina com o transporte das árvores para unidades de processamento (MARTINS et al., 1998). Porém a exploração florestal sem planejamento, realizada de maneira intensa e seletiva na Amazônia, tem transformado florestas de elevado estoque de madeira e valor comercial em florestas degradadas, de baixo valor comercial e de difícil recuperação (PINTO et al., 2002).

Dessa forma, as técnicas de manejo florestal de impacto reduzido, considerando microzoneamento, planejamento da exploração, seleção de espécies e corte direcionado das árvores, são projetadas para reduzir o impacto do tráfego de máquinas pesadas nos solos, reduzir o volume de madeira desperdiçada na extração e aumentar a segurança do trabalhador na derrubada das árvores (HOLMES et al., 2002). De acordo com a capacidade da empresa, pode ser sugerida uma maior ou menor complexidade no planejamento (BRAZ, 2005). Entretanto, pouco tem sido considerado com relação à otimização temporal das atividades, principalmente quando há limitantes, como estação das chuvas, ou outro qualquer fator que possa impedir o início dos trabalhos em tempo hábil.

Nas florestas nativas, além de toda a complexidade de sua composição, com um grande número de espécies com as mais diferentes características silviculturais, ecológicas e tecnológicas, alguns dos importantes pontos a serem abordados são: definição do ciclo de corte, suscetibilidade das espécies florestais à exploração, economicidade do manejo sustentado, aumento da eficiência no processo de beneficiamento e aproveitamento da madeira e racionalização das técnicas de exploração e transporte (SCOLFORO et al., 1996).

O engenheiro responsável pelo planejamento se depara, então, com determinados problemas, como seleção do sistema de exploração, escolha de equipamento adequado ao sistema, elaboração de um planejamento de estradas secundárias, compatível com os custos de construção e com o potencial da floresta, e, finalmente, conclusão das tarefas nas datas previstas, que, muitas vezes, dependem dos fatores climáticos. Junto aos fatores climáticos, a empresa florestal depende da liberação pelo órgão fiscalizador do talhão ou talhões para o ano de exploração. Isso cria um complicador quando o ano está finalizando e o período adequado à extração se encerrando.

Dentre os vários modelos de suporte à decisão, os modelos de pesquisa operacional (PO) ocupam papel de destaque na alocação ótima dos recursos entre as diversas atividades competitivas (RODRIGUES et al., 2006). A pesquisa operacional consiste na descrição de um sistema organizado com o auxílio de um modelo, e através da experimentação com o modelo, na descoberta da melhor maneira de operar o sistema (SILVA et al., 1995). Entretanto, apesar da existência dessas ferramentas, as quais objetivam a melhoria da qualidade da exploração das florestas naturais, elas são pouco utilizadas. Na verdade, desconhece-se a maioria dessas técnicas e sua compatibilidade com a exploração e manejo das florestas nativas (BRAZ, 2005).

Dessa forma, objetiva-se neste trabalho a utilização de técnicas de pesquisa operacional para determinar o caminho crítico e as atividades "gargalo" do processo de exploração de madeira nativa. Mais especificamente, objetiva-se determinar, por meio da formulação de cenários, o número ideal de equipes necessárias para a realização da exploração florestal no manejo de baixo impacto, de modo a se enquadrar no tempo limite pelo período fora da estação das chuvas, considerando aqui a execução de todas as atividades sob essas condições.

\section{MATERIAL E MÉTODOS}

O estudo foi realizado na área de uma empresa situada no estado do Amazonas, perto da divisa com os estados do Acre e Rondônia. A área da propriedade destinada para manejo é de 2.000 ha, dos quais 1.000 ha foram utilizados no presente estudo.

Para essa área de estudo, foram estimados $30.000 \mathrm{~m}^{3}$ de volume total, um total de 20.000 metros de estradas e 67 pátios. Entre as espécies, foram selecionadas 26 com potencial econômico e de extração. 
A escolha deveu-se principalmente à preferência da empresa em trabalhar com essas espécies, devido ao seu potencial imediato de comercialização e ao mercado a que se destinam.

O clima, segundo a classificação de Köppen (1948), é do tipo Am: clima quente e úmido de monções, com estação seca bem definida entre os meses de junho e outubro, seguido de estação chuvosa, com temperatura média anual de $25^{\circ} \mathrm{C}$, umidade relativa do ar de $85 \%$ e precipitação anual de $2.250 \mathrm{~mm}$.

A floresta predominante na área é densa, com árvores emergentes, ocorrendo também tipologias de florestas abertas com bambu e palmeiras. Quanto ao relevo, é suavemente ondulado, com algumas áreas com inclinação forte. A área apresenta alguns cursos d'água apenas temporários.

As atividades necessárias para a exploração de florestas nativas no manejo de baixo impacto foram fornecidas pela empresa e estão descritas a seguir, de acordo com os conceitos de Machado (2008) e do Instituto Brasileiro do Meio Ambiente e dos Recursos Naturais Renováveis (IBAMA, 2012):

1. "Delimitação da área de exploração, picadas e sinalização": mapeamento das Unidades de Produção Anuais (UPAs) a partir de um planejamento prévio com auxílio de um GPS de navegação, abertura de picadas de delimitação da UPA com auxílio de uma bússola e colocação de placas indicativas;

2. "Levantamento das áreas com microzoneamento": identificação e plaqueamento das árvores objeto do manejo com diâmetro à altura do peito (DAP) maior que $50 \mathrm{~cm}$. Identificação e observância das áreas de preservação permanente, cipoais, variações topográficas, corpos d'água etc;

3. "Tratamentos silviculturais": corte de cipós que interligam as árvores. Tem como objetivo facilitar o direcionamento de derrubada das árvores selecionadas, diminuindo, assim, de forma acentuada os danos causados às árvores remanescentes;

4. "Planejamento das estradas": o planejamento busca uma combinação entre distância ótima, densidade, forma fundamental de rede, classes de estradas e disposição dos estaleiros, tal que os custos de arraste, transporte e construção das estradas sejam mínimos, nas condições consideradas;

5. "Planejamento de arraste e marcação das trilhas": balizamento inicial do terreno em trilhas ideais de arraste para ganhos na redução do tempo de extração e menores danos à floresta. O objetivo é definir, através de sinais normalizados, a trilha a ser percorrida pelo trator florestal, facilitar a orientação do operador do trator durante o arraste das toras, aumentar a produtividade e diminuir substancialmente o dano à floresta remanescente;

6. "Abertura de estradas e pátios de estocagem": construção da rede de estradas para extração e transporte final e construção do local para empilhar e estocar as toras antes do transporte até a indústria (trator esteira $200 \mathrm{HP}$ ). Devem estar próximos às estradas secundárias e/ou primárias;

7. "Abate e traçamento das árvores": abate é o ato ou efeito de cortar a árvore e direcionar sua queda, visando diminuir o dano às árvores potencialmente comerciais, que permanecerão para o próximo ciclo.

8. "Manutenção das estradas": operações de recuperação de estradas primárias, secundárias e pátios de estocagem após as atividades de pós-exploração;

9. "Extração por arraste mecanizado": retirada da madeira, mediante trator de arraste (skidder $160 \mathrm{HP}$ ), do interior do talhão até a estrada. Nesse caso, extração por arraste, feita por skidder de cabo, em que toda a carga ou parte dela está apoiada sobre o solo;

10. "Medição das toras": no pátio, todas as toras são medidas em seu diâmetro e seu comprimento e ganham uma etiqueta com a mesma numeração recebida no censo florestal;

11. "Carregamento das toras": carregamento dos caminhões mediante carregadora frontal (160 HP);

12. "Transporte final": transporte por caminhão (20 ton) da madeira explorada, da estrada até seu destino final.

As técnicas de Program Evaluation and Review Technique (PERT) e Critical Path Method (CPM) auxiliam os gestores florestais na tomada de decisões, controlando o tempo de execução de um projeto. Tais técnicas levam em conta as condições especiais na duração das atividades, sem, todavia, se ocupar com o seu controle (BRUM, 1977).

O PERT/CPM é uma sequência de atividades que representam, em um gráfico, o início e a conclusão de um evento, bem como as demais atividades intermediárias. Um evento só poderá ser considerado iniciado quando todas as atividades que a ele concorrem forem concluídas. Assim, as atividades que não são executadas dentro do tempo determinado e acabam atrasando o tempo total do projeto são chamadas de atividades "gargalo", ou críticas.

Através da utilização do PERT/CPM, foi proposto o Cenário 1, com a finalidade de encontrar as atividades "gargalo" e o caminho crítico na exploração florestal de madeira nativa, além do tempo 
necessário para finalizar toda a atividade, livre de restrições, levando em consideração apenas uma equipe por atividade.

No Cenário 2, foi realizada uma extrapolação dos dados encontrados no PERT/COM, a fim de demostrar uma forma manual de adequar o número de equipes ao tempo limite máximo de 168 dias.

Entre as técnicas matemáticas para planejar a alocação de recursos limitados, tem-se a programação linear, que consiste na maximização ou minimização de uma função linear de variáveis primárias denominada função objetivo, sujeita a um conjunto de igualdades ou desigualdades lineares, denominadas de restrições (BERGER et al., 2003).

Posteriormente, foi utilizada a programação linear na formulação e geração dos Cenários 3 e 4, com a finalidade de adequar o processo à restrição de tempo e quantificar o número ideal de equipes em cada atividade do processo de exploração florestal.

A base do modelo utilizado foi linear, embora a divisão dos tempos de execução das atividades pelo número de equipes envolvidas tenha gerado relações não lineares nas variáveis. Portanto, o solver Language for Interactive General Optimizer (LINGO) foi utilizado para resolver problemas não lineares, como instrumento para o planejamento das atividades de exploração de florestas nativas, supondo a formulação do problema delimitado por restrições e sua posterior combinação.

A proposição do Cenário 3 visou a minimização do número de equipes, permitindo que a duração das atividades seja fracionada em números (não inteiros) de dias. No Cenário 4, manteve-se como objetivo a minimização do número de equipes, acrescentando-se a restrição de que a duração das atividades deva ser composta por números inteiros ou dias completos.

Os Cenários 3 e 4 apresentados representaram um modelo de programação linear com variáveis contínuas e inteiras, respectivamente, considerando a seguinte função objetivo e conjunto de restrições:

Função-Objetivo: Minimização do número de equipes

$$
\operatorname{Min} \mathrm{z}=\mathrm{x}_{1}+\mathrm{x}_{2}+\ldots+\mathrm{x}_{12}
$$

Sujeito a:

- Restrição de tempo:

Essa restrição garante que as atividades sejam executadas, a fim de atender a necessidade de compatibilizar o processo de exploração com o tempo máximo para extração da madeira na região. $\mathrm{O}$ tempo máximo para finalização da cadeia é delimitado pelo seu período chuvoso, que ocorre, segundo Fisch et al. (1998), entre novembro e março. Dessa maneira, o processo deve ser planejado para ocorrer em sete meses, abrangendo 168 dias de trabalho.

- Restrição de sequenciamento:

$$
\frac{d_{1}}{x_{1}}+\frac{d_{2}}{x_{2}}+\ldots+\frac{d_{12}}{x_{12}} \leq 168 \text { dias }
$$
predecessora.

Essa restrição garante que uma atividade só comece após o término de sua atividade

Em que $k$ é predecessor de $i$.

- Restrição de pausa (delay):

Essa restrição permite que as atividades possam acontecer de forma simultânea ou concomitante, ou com alguns dias de anacronismo. Em outras palavras, algumas atividades podem começar antes do término de sua atividade predecessora.

Para as atividades consideradas simultâneas ou concomitantes, a pausa aplicada foi zero, isto é, as atividades iniciaram de forma simultânea ou concomitante. As atividades anacrônicas tiveram pausa de dois ou cinco dias, dependendo de seu tempo de espera. As demais atividades não concomitantes nem anacrônicas tiveram pausa completa e foram tratadas normalmente, tendo seu início apenas após o término de todas as predecessoras.

- Condição de não negatividade:

$$
\mathrm{x}_{i} \geq 0
$$


Em que: $\quad \mathrm{i}=$ atividades $1,2,3, \ldots, 12$;

$\boldsymbol{d}_{i}=$ duração (dias) da atividade i considerando uma única equipe;

$\mathbf{x}_{\mathbf{i}}=$ número de equipes que executam a atividade $\mathrm{i}$;

$\mathrm{ki}=$ conjunto das atividades predecessoras da atividade $\mathrm{i}$;

$\mathrm{Eti}=$ primeiro momento $(\mathrm{dia})$ para iniciar a atividade $\mathrm{i}$;

$\mathrm{Lti}=$ último momento (dia) para iniciar a atividade $\mathrm{i}$.

- Restrição adicional do Cenário 4

Nesse cenário, a variável $x_{i}$, que representa o número de equipes a executar a atividade $i$, deve ser inteira.

$$
\mathrm{x}_{\mathrm{i}} \in 0,1,2, \cdots, \mathrm{N}
$$

Para a resolução dos Cenários 1, 3 e 4, foi utilizado o software Extended LINGO PC versão 13 64 bits, com solvers linear, barrier e global, licenciado para o Laboratório de Manejo Florestal da UFPR. O LINGO é um software desenvolvido pela LINDO Sistem's Inc. para resolver problemas de otimização envolvendo programação linear, programação linear inteira e programação não linear.

\section{RESULTADOS E DISCUSSÃO}

A resolução do Cenário 1 com o auxílio da ferramenta PERT/CPM mostra que, se não for imposta nenhuma restrição ao sequenciamento das atividades e se elas forem executadas com apenas uma equipe cada, o processo de exploração ocorrerá em 1.000 dias, resultado do somatório da variável "Último momento para iniciar a atividade Transporte final" $(L T), 850$ dias, com seu tempo de execução de 150 dias, como demonstrado na tabela 1 .

Tabela 1. Período de exploração de madeiras nativas para o Cenário 1.

Table 1. Exploitation period of the native timber for Scenario 1.

\begin{tabular}{|c|c|c|c|c|c|}
\hline \multirow{2}{*}{ Atividades da exploração de madeira nativa } & \multirow{2}{*}{ Produtividade } & \multirow{2}{*}{ Duração } & \multicolumn{2}{|c|}{ Tempo (dias) } & \multirow{2}{*}{ Folga } \\
\hline & & & ET & LT & \\
\hline 1. Delimitação da área de exploração & $30 \mathrm{ha} / \mathrm{dia}$ & 33 & 0 & 0 & 0 \\
\hline 2. Levantamento das áreas & $20 \mathrm{ha} / \mathrm{dia}$ & 50 & 33 & 33 & 0 \\
\hline 3. Tratamentos silviculturais & $33 \mathrm{ha} / \mathrm{dia}$ & 30 & 83 & 184 & 101 \\
\hline 4. Planejamento das estradas & $50 \mathrm{ha} / \mathrm{dia}$ & 20 & 83 & 83 & 0 \\
\hline \multirow{2}{*}{$\begin{array}{l}\text { 5. Planejamento de arraste e marcação das trilhas } \\
\text { Dummy } 1\end{array}$} & $350 \mathrm{ha} / \mathrm{dia}$ & 86 & 103 & 103 & 0 \\
\hline & & 0 & 189 & 189 & 0 \\
\hline \multirow{2}{*}{$\begin{array}{l}\text { 6. Abertura de estradas e pátios de estocagem } \\
\text { Dummy } 3\end{array}$} & $800 \mathrm{~m} / \mathrm{dia}$ & 25 & 189 & 189 & 0 \\
\hline & & 0 & 113 & 214 & 101 \\
\hline 7. Abate e traçamento das árvores & $120 \mathrm{~m}^{3} / \mathrm{dia}$ & 250 & 214 & 214 & 0 \\
\hline \multirow{2}{*}{$\begin{array}{l}\text { 8. Manutenção das estradas } \\
\text { Dummy } 2\end{array}$} & $2.000 \mathrm{~m} / \mathrm{dia}$ & 10 & 214 & 840 & 626 \\
\hline & & 0 & 224 & 850 & 626 \\
\hline 9. Extração por arraste mecanizado & $200 \mathrm{~m}^{3} / \mathrm{dia}$ & 150 & 464 & 464 & 0 \\
\hline 10. Medição das toras & $350 \mathrm{~m}^{3} / \mathrm{dia}$ & 86 & 614 & 614 & 0 \\
\hline 11. Carregamento das toras & $200 \mathrm{~m}^{3} / \mathrm{dia}$ & 150 & 700 & 700 & 0 \\
\hline 12. Transporte final & $200 \mathrm{~m}^{3} / \mathrm{dia}$ & 150 & 850 & 850 & 0 \\
\hline
\end{tabular}

ET: primeiro momento (dia) para iniciar a atividade i; LT: último momento (dia) para iniciar a atividade i.

Observando-se os valores de "Primeiro momento de início" (ET) e do "Último momento de início" ( $L T)$ obtidos no PERT/CPM sem restrições, verifica-se que a maioria das atividades possui folga zero. A folga (slack) corresponde ao tempo que uma atividade pode atrasar sem que comprometa o prazo de término total do empreendimento. Por exemplo, a atividade número 9, "Extração por arraste mecanizado", possui o seu "Primeiro momento de início" no dia 464, coincidentemente com seu "Último momento de início", também no dia 464. Em outras palavras, essa atividade deve começar, impreterivelmente, no dia 464. A figura 1 apresenta o caminho crítico, caracterizado pela sequência das atividades com folga zero, do Cenário 1. 


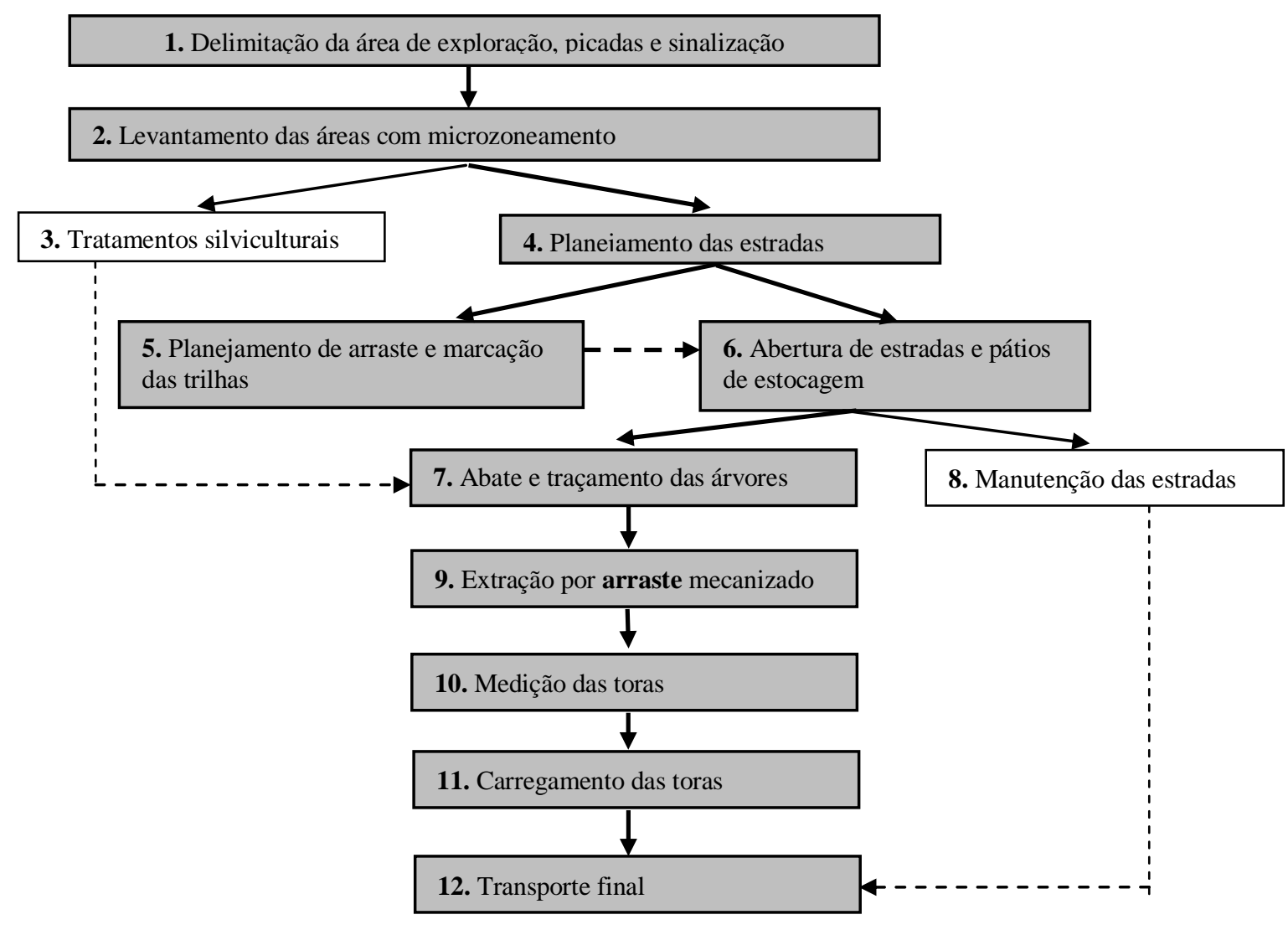

Figura 1. Caminho crítico das atividades de exploração de florestas nativas.

Figure 1. Critical path of native forests exploration.

$\mathrm{O}$ direcionamento das setas indica o sequenciamento das atividades. As setas em negrito e as atividades em cinza apresentam o caminho crítico com todas as atividades que possuem folga zero, e as setas tracejadas representam as atividades artificiais, ou dummy. As atividades que constituem o caminho crítico devem receber o foco do controle de planejamento.

Sabe-se que essa área específica da região amazônica possui apenas sete meses de estação seca, sendo que a extração da madeira nativa deve, necessariamente, ser realizada nesse período, já que no período chuvoso as atividades, principalmente de "Extração por arraste mecanizado" e "Transporte final", ficam dificultadas. Com isso, o tempo de 1.000 dias encontrado no sequenciamento das atividades pelo PERT/CPM simples (Tabela 1) não é aplicável na prática. Portanto, para resolver essas dificuldades, foi formulado o Cenário 2, calculando-se, de forma manual, o número de equipes necessárias para adequar o tempo em 168 dias (Figura 2).

Verifica-se que, sem a ajuda de uma ferramenta de auxílio, o gestor florestal poderia adequar, manualmente, a conclusão das atividades ao tempo limite, fazendo uma extrapolação a partir do tempo encontrado no PERT/CPM. Se com apenas uma equipe por atividade o empreendimento demora 1.000 dias para finalizar, para que o empreendimento finalize em menos que 168 dias serão necessárias 6 equipes em cada atividade. No entanto, sabe-se que cada atividade de exploração necessita um número diferente de equipes para sua execução, cada uma com diversas necessidades e objetivos, pessoais e profissionais, de acordo com dificuldades e tempo de execução.

Tendo essa situação em vista, os Cenários 3 e 4 utilizam a programação linear para facilitar o planejamento e a adequação do número ideal de equipes para cada atividade pelos gestores do empreendimento. Os Cenários 3 e 4 foram resolvidos por meio do software LINGO. Nesses cenários, não há mais folgas (slacks), pois nenhuma atividade termina antes do prazo máximo permitido, devido ao fato 
de se querer sempre minimizar o número de equipes. No Cenário 3, a função objetivo utilizada foi a de minimizar o número de equipes, respeitando a restrição de manter o prazo de execução em, no máximo, 168 dias (Tabela 2).

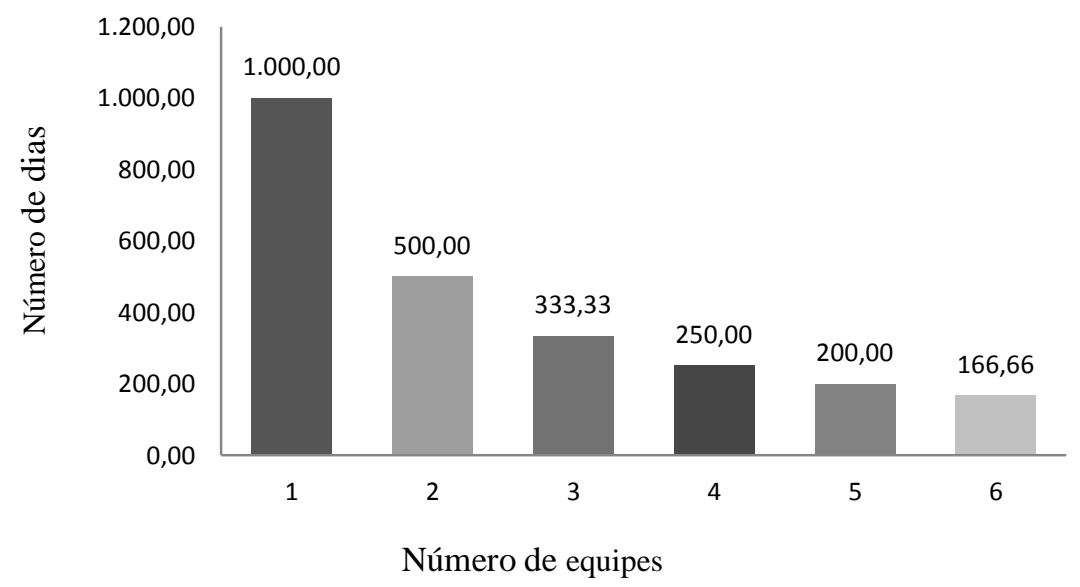

Figura 2. Número de equipes por atividades da exploração de madeiras nativas para o Cenário 2.

Figure 2. Number of teams for the native woods exploitation activities for Scenario 2.

Tabela 2. Número mínimo de equipes para cada atividade da exploração de madeiras nativas para o Cenário 3.

Table 2. Minimum number of teams for each activity of native timber exploitation for Scenario 3.

\begin{tabular}{llcccc}
\hline \multirow{2}{*}{ Atividades da exploração de madeiras nativas } & \multirow{2}{*}{ Pausa } & \multicolumn{2}{c}{ Tempo (dias) } & Número \\
\cline { 3 - 4 } & & ET & LT & equipes \\
\hline 1. Delimitação área de exploração, picadas e sinalização & - & 0,00 & 0,00 & 2,07 \\
2. Levantamento das áreas com microzoneamento & - & 15,94 & 15,94 & 2,54 \\
3. Tratamentos silviculturais & - & 35,53 & 35,53 & 1,00 \\
4. Planejamento das estradas & - & 35,53 & 35,53 & 1,61 \\
5. Planejamento de arraste e marcação das trilhas & - & 47,94 & 47,94 & 3,34 \\
6. Abertura de estradas e pátios de estocagem & - & 73,65 & 73,65 & 1,00 \\
7. Abate e traçamento das árvores & 5,00 & 78,65 & 78,65 & 3,03 \\
8. Manutenção das estradas & - & 98,65 & 98,65 & 1,00 \\
9. Extração por arraste mecanizado & 2,00 & 80,65 & 80,65 & 1,82 \\
10. Medição das toras & 0,00 & 80,65 & 80,65 & 1,04 \\
11. Carregamento das toras & 0,00 & 80,65 & 80,65 & 1,82 \\
12. Transporte final & 5,00 & 103,65 & 103,65 & 2,33 \\
\hline Número total téorico de equipes & & & & 22,63 \\
\hline
\end{tabular}

ET: primeiro momento (dia) para iniciar a atividade i; LT: último momento (dia) para iniciar a atividade i.

Tomando como exemplo a atividade 7, "Abate e traçamento das árvores", verifica-se, primeiramente, que tal atividade possui uma pausa de 5 dias em relação à sua atividade antecessora, ou seja, como a atividade 6 tem início no dia 73,65, a atividade 7 poderá ter seu início no dia 78,65 (cinco dias após o começo da sua atividade anterior). A atividade 7 demoraria, com uma equipe (Cenário 1), 250 dias para ser finalizada, porém nesse cenário são utilizadas 3,03 equipes de trabalho nessa tarefa, para que a atividade não exceda o tempo limite máximo.

Dessa forma, ela deverá ser finalizada em 82,50 dias, terminando sua jornada no dia 161,15 $(73,65+82,50)$. A próxima atividade no sequenciamento, "Extração por arraste mecanizado", começará no dia 80,65 , dois dias após sua atividade antecessora, "Abate e traçamento das árvores" dar seu início, 
permanecendo ativa por 82,41 dias e finalizando suas atividades no dia 163,06, resultado do somatório da duração da atividade pelo número de equipes, com o dia de início da atividade.

E assim, como apresentado no gráfico de barras (Figura 3), seguirão sucessivamente as demais atividades, até o transporte final finalizar no dia 168.

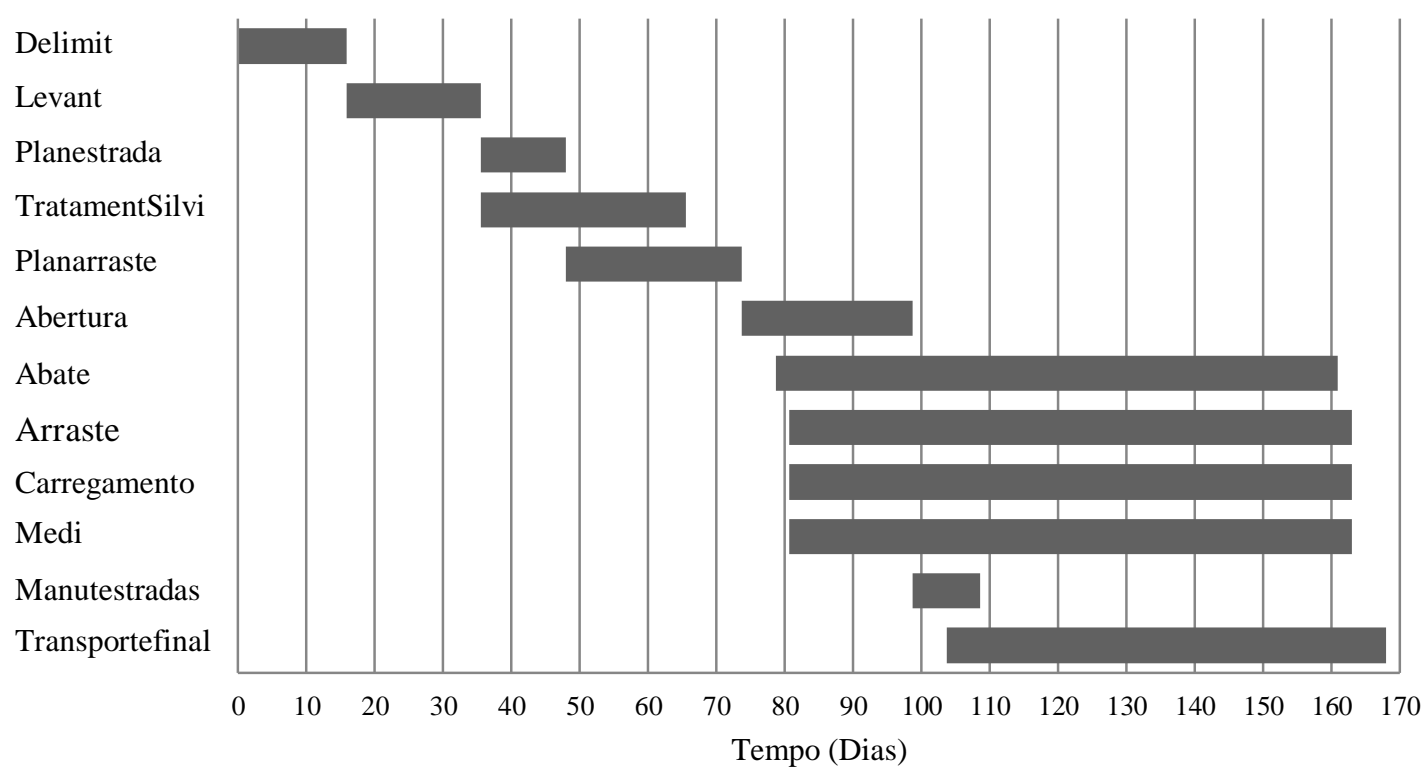

Figura 3. Sequenciamento das atividades para o Cenário 3.

Figure 3. Sequence of the activities for Scenario 3.

Silva et al. (2003) provaram que, do ponto de vista matemático, em problemas de regulação florestal, soluções operacionais resultantes de arredondamentos da solução obtida via programação linear não devem ser adotadas, pois podem levar ao não atendimento das restrições, além de não garantirem os objetivos de otimização, quais sejam, os de maximizar ou minimizar uma função-objetivo qualquer. Dessa forma, propõem-se o Cenário 4, em que se mantém a mesma função-objetivo de minimização do número de equipes e as mesmas restrições de tempo. No entanto, esse cenário acrescenta a restrição de que o número de equipes seja inteiro, de forma a ajudar ainda mais o gestor na tomada de decisão de alocação de equipes.

Os dados do Cenário 4, como podem ser vistos na tabela 3, não diferem muito do cenário anterior, porém nos levam para uma análise mais próxima da encontrada em campo. A análise das datas de "Primeiro" e "Último momento para iniciar as atividades" e suas pausas deve possuir o mesmo sequenciamento lógico do Cenário 3, como apresentado no gráfico de barras, figura 4.

O processo de gestão do abastecimento florestal através da retirada de madeira das florestas nativas é uma atividade de alto risco, pois se processa em meio a atividades que devem ocorrer dentro do período predeterminado pelo planejamento, com o número ideal de equipes. Qualquer atraso nas atividades intermediárias será refletido no prazo final da exploração, podendo ocasionar a perda da operação e de todos os recursos alocados no empreendimento. A tabela 4 apresenta de maneira comparativa os resultados encontrados para os quatro cenários propostos.

Percebe-se que, com a ajuda da programação matemática, há um planejamento melhor das atividades. No Cenário 1, sem qualquer restrição e considerando apenas uma equipe para executar cada atividade, o gestor adentraria o período de chuvas e não conseguiria concluir a operação com sucesso. $\mathrm{O}$ Cenário 2, que consiste em tentar, manualmente, adequar as atividades a um tempo máximo, identificou o número ideal de 72 equipes ao todo, o que, a partir da análise dos Cenários 3 e 4, resulta em um número muito elevado de equipes alocadas para as atividades. 
Tabela 3. Número mínimo de equipes para cada atividade da exploração de madeira nativas para o Cenário 4.

Table 3. Minimum number of teams for each activity of native timber exploitation for Scenario 4.

\begin{tabular}{lcccc}
\hline \multirow{2}{*}{ Atividades da exploração de madeiras nativas } & \multirow{2}{*}{ Pausa } & \multicolumn{2}{c}{ Tempo (dias) } & \multirow{2}{*}{$\begin{array}{c}\text { Número } \\
\text { equipes }\end{array}$} \\
\cline { 3 - 5 } 1. Delimitação área de exploração, picadas e sinalização & - & 0,00 & 0,00 & 3,00 \\
2. Levantamento das áreas com microzoneamento & - & 11,00 & 11,00 & 3,00 \\
3. Tratamentos silviculturais & - & 28,21 & 28,21 & 1,00 \\
4. Planejamento das estradas & - & 28,21 & 28,21 & 2,00 \\
5. Planejamento de arraste e marcação das trilhas & - & 39,09 & 39,09 & 4,00 \\
6. Abertura de estradas e pátios de estocagem & - & 61,66 & 61,66 & 1,00 \\
7. Abate e traçamento das árvores & 5,00 & 66,66 & 66,66 & 3,00 \\
8. Manutenção das estradas & - & 86,66 & 86,66 & 2,00 \\
9. Extração por arraste mecanizado & 2,00 & 77,00 & 77,00 & 2,00 \\
10. Medição das toras & 0,00 & 77,00 & 77,00 & 1,00 \\
11. Carregamento das toras & 0,00 & 88,00 & 88,00 & 2,00 \\
12. Transporte final & 5,00 & 93,00 & 93,00 & 2,00 \\
\hline Número total teórico de equipes & & & & 25,00 \\
\hline
\end{tabular}

ET: primeiro momento (dia) para iniciar a atividade i; LT: último momento (dia) para iniciar a atividade i.

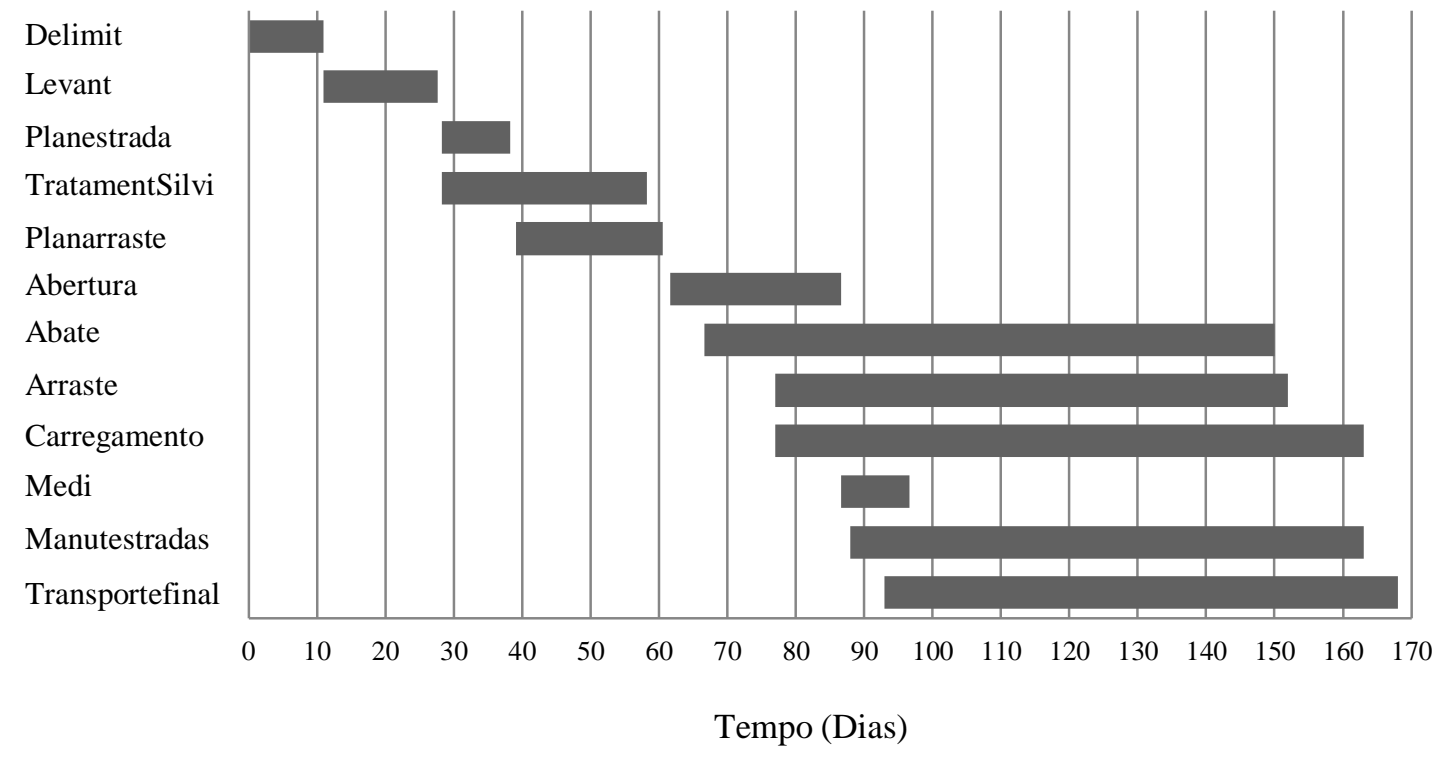

Figura 4. Sequenciamento das atividades para o Cenário 4.

Figure 4. Sequence of the activities for Scenario 4.

Tabela 4. Resultados finais para os cenários propostos.

Table 4. Final results for the proposed scenarios.

\begin{tabular}{lcc}
\hline Cenários & Número de equipes & Tempo final de execução (dias) \\
\hline 1 & 12,00 & $1.000,00$ \\
2 & 72,00 & 166,66 \\
3 & 22,63 & 168,00 \\
4 & 25,00 & 168,00 \\
\hline
\end{tabular}

O modelo é ágil e pode ser modificado para selecionar apenas as atividades impossíveis de serem realizadas em período chuvoso, ou retirar aquelas que foram realizadas com antecedência, em outro período. 


\section{CONCLUSÃO}

- A utilização de ferramentas da pesquisa operacional permite planejar as operações de exploração nos períodos sem chuva na região.

- O sequenciamento das atividades de exploração e manejo florestal de madeiras nativas torna todas as suas atividades integrantes do caminho crítico. Apenas as atividades de "Tratamentos silviculturais", predecessora do "Abate e traçamento das árvores", e "Manutenção das estradas", predecessora do "Transporte final", não são críticas.

- No Cenário 2, que considera o mesmo número de equipes para todas as atividades, são necessárias seis equipes por atividade para adequar o tempo limite de exploração na região em, no máximo, 166,66 dias de trabalho.

- No Cenário 3, o número de equipes varia entre 1,00 (“Abertura de estradas e pátios de estocagem, Manutenção das estradas e Tratamentos silviculturais") e 3,34 equipes ("Planejamento de Arraste"), totalizando 22,63 equipes para que toda exploração ocorra em 168 dias. Já no Cenário 4, similar ao cenário 3, porém com números de equipes inteiras, as mesmas variam entre 1 e 4, com um total de 25 equipes, finalizando as atividades também em 168 dias.

\section{AGRADECIMENTOS}

Este estudo foi parcialmente financiado pelo Conselho Nacional de Desenvolvimento Científico e Tecnológico (CNPq) e pela Coordenação de Aperfeiçoamento de Pessoal de Nível Superior (CAPES), através da bolsa de Reestruturação e Extensão das Universidades Federais (REUNI). Os autores são gratos ainda ao Laboratório de Manejo Florestal e ao Laboratório de Economia Florestal Aplicada da Universidade Federal do Paraná (UFPR); à colaboração dos integrantes da equipe de campo, na pessoa de Fábio Thaines, da empresa em Consultoria Tecnologia e Manejo Florestal (Tecman) do estado do Acre; e a Dayanne Cristyne de Souza Moura, residente florestal em trabalho de pesquisa da EMBRAPA Acre, pelo auxílio na atualização dos dados.

\section{REFERÊNCIAS}

BERGER, R.; TIMOFEICZYK Jr, R; CARNIERI, C.; LACOWICZ, P. G.; SAWINSKI Jr., J.; BRASIL, A. A. Minimização de custos de transporte florestal com a utilização da programação linear. Floresta, v. 33, n. 1, p. $53-62,2003$.

BRAZ, E. M. Planejamento da exploração em florestas naturais. $1^{\text {a }}$ ed., Dados eletrônicos. - Colombo: Embrapa Florestas, 2005, 29 p.

BRUM, E. T.; ABREU, P. S. C.; OLIVEIRA, Y. M. M. Utilidade da rede PERT/CPM no setor florestal. Floresta, v. 8, n. 2, p. 33 - 46, 1977.

INSTITUTO BRASILEIRO DO MEIO AMBIENTE E RECURSOS NATURAIS RENOVÁVEIS (IBAMA). Verificadores e indicadores. Diponível em: <\%20http:/www.ibama.gov.br/areastematicas/verificadores-e-identificadores\%20>. Acesso em: 28/06/2012.

FISCH, G.; MARENGO, J. A.; NOBRE, C. A. Uma revisão geral sobre o clima da Amazônia. Acta Amazônica, v. 28, n. 2, p. 101 - 126, 1998.

GAMA, J. R. V.; BENTES-GAMA, M. M.; SCOLFORO, J. R. S. Manejo sustentado para Floresta de Várzea na Amazônia Oriental. Árvore, v. 29, n. 5, p. 719 - 729, 2005.

HOLMES, T. P.; BLATE, G. M.; ZWEEDE, J. C.; PEREIRA JUNIOR, R.; BARRETO, P.; BOLTZ, F. Custos e benefícios financeiros da exploração de impacto reduzido em comparação à exploração florestal convencional na Amazônia Oriental. 2da Ed. Belém: Fundação Floresta Tropical, 2002, 66 p.

KÖPPEN, W. Climatologia: Con un estudio de los climas de La tierra. Fondo de Cultura Econômica. México. 479p. 1948. Disponível em: <http://pt.scribd.com/doc/55213396/KOEPPEN-1948-ClimatologiaCon-un-estudio-de-los-climas-de-la-Tierra>. Acesso em: 28/06/2012. 
PINHO, G. S. C.; FIEDLER, N. C.; GUIMARAES, P. P.; SILVA, G. F.; SANTOS, J. Análise de custos e rendimentos de diferentes métodos de corte de cipós para produção de madeira na floresta nacional de Tapajós. Acta Amazonica, v. 39, n. 3, p. 555 - 560, 2009.

PINTO, A. C. M.; SOUZA, A. L.; SOUZA, A. P.; MACHADO, C. C.; MINETTE, L. J.; VALE, A. B.. Análise de danos de colheita de madeira em floresta tropical úmida sob regime de manejo florestal sustentado na Amazônia Ocidental. Árvore, v. 26, n. 4, p. 459 - 466, 2002.

MACHADO, C. C. Colheita Florestal. 2da ed. Editora UFV, Viçosa, 2008, 501 p.

MARTINS, S. S.; COUTO, L.; TORMENA, C. A.; MACHADO, C. C. Impactos da exploração madeireira em florestas nativas sobre alguns atributos físicos do solo. Árvore, v. 22, n. 1, p. 69 - 76 , 1998.

RODRIGUES, F. L.; SILVA, G. F.; LEITE, H. G.; XAVIER, A. C.; PEZZOPANE, J. E. M.. Um modelo de regulação florestal e suas implicações na formulação e solução de problemas com restrições de recobrimento. Árvore, v. 30, n. 5, p. 769 - 778, 2006.

SCOLFORO, J. R. S.; PULTZ, F. A.; MELlO, J. M.; OLIVEIRA FILHO, A. T. Modelo de produção para floresta nativa como base para manejo sustentado. Cerne, v. 2, n. 1, p. 112 - 137, 1996.

SILVA, E. M.; SILVA, E. M.; GONÇALVES, V.; MUROLO, A. C. Pesquisa operacional. São Paulo: Ed. Atlas, 1995.

SILVA, G. F.; LEITE, H. G.; SILVA, M. L.; RODRIGUES, F. L.; SANTOS, H. N. Problemas com o uso de programação linear com posterior arredondamento da solução ótima, em regulação florestal. Árvore, v. 27, n. 5 , p. 677 - $688,2003$. 
